\title{
Luiz Roberto Vialle (ed): AO spine masters series-Volume 10 spinal infections
}

\section{Thieme Verlag New York, Stuttgart, Delhi, Rio de Janeiro, July 2018, 202 pp, 86 illustr., Hardback € 109.99, ISBN: 978-1-62623-455-0, E-Book ISBN: 978-1-62623-456-7}

\author{
Alain G. Graftiaux ${ }^{1}$. Pierre H. Kehr ${ }^{1}$
}

Received: 10 August 2019 / Accepted: 14 September 2019 / Published online: 30 September 2019

○ Springer-Verlag France SAS, part of Springer Nature 2019

The tenth book in the AO spine masters series, this series provides useful information on a particular topic: here, infections in spine surgery. Infections are an important topic because if the diagnosis is delayed or if the treatment is inappropriate the result is likely to be bad with adverse consequences for the patient.

The first chapters concern generalities: epidemiology, imagery, etc.

The following chapters deal with the different pathologies: spondylodiscitis, pyogenic abscess, epidural abscess, tuberculosis, HIV infections, postoperative infections, infections in elderly subjects...

Each chapter has a short bibliography, as well as a very useful pearls/pitfalls part.
This book will be of interest to all spine surgeons (orthopedists and neurosurgeons), young or confirmed. They can find answers to the questions they ask themselves, especially in difficult or particular cases.

\section{Compliance with ethical standards}

Conflict of interest The author(s) declare that they have no competing interest.

Publisher's Note Springer Nature remains neutral with regard to jurisdictional claims in published maps and institutional affiliations.
Pierre H. Kehr

pierre.kehr@gmail.com

1 University of Strasbourg, Strasbourg, France 